\title{
Distribution of Impurities between Crude Copper, White Metal and Silica-Saturated Slag*
}

\author{
By Masaru Kashima**, Motonori Eguchi*** and Akira Yazawa***
}

\begin{abstract}
Distribution behavior of minor elements has important implications for copper making processes. In this article, the experimental results of the distribution of silver, nickel, cobalt, lead, antimony and arsenic among the three melts of copper, white metal and silica-saturated iron silicate slag are described.

The melting experiments were carried out at $1300^{\circ} \mathrm{C}$ under controlled $\mathrm{SO}_{2}$ partial pressures varying from 0.7 to $20 \mathrm{kPa}$ which are approximately proportional to the $\mathrm{O}_{2}$ pressures.

The distribution ratios for an element $\mathrm{X}$, defined as,

$$
\begin{aligned}
& L_{\mathbf{x}}^{c / s}=\% \mathrm{X} \text { in metal } / \% \mathrm{X} \text { in slag } \\
& L_{\mathbf{x}}^{c / w}=\% \mathrm{X} \text { in metal } / \% \mathrm{X} \text { in white metal } \\
& L_{\mathbf{x}}^{w / s}=\% \mathrm{X} \text { in white metal } / \% \mathrm{X} \text { in slag }
\end{aligned}
$$

can be arranged in the following orders:

$$
\begin{aligned}
& L^{c / s}: \mathrm{As},(\mathrm{Ag})>\mathrm{Sb}>\mathrm{Ni}>\mathrm{Pb}>\mathrm{Co} \\
& L^{c / w}: \mathrm{As}>\mathrm{Sb}>\mathrm{Pb}, \mathrm{Ni},(\mathrm{Ag})>\mathrm{Co} \\
& L^{w / s}:(\mathrm{Ag})>\mathrm{As}>\mathrm{Sb}>\mathrm{Ni}>\mathrm{Pb}>\mathrm{Co} .
\end{aligned}
$$

Thus, the impurity elements in this study can be grouped into three classes according to distribution tendencies: As and $\mathrm{Sb}$ are highly concentrated in the metal, Co is highly concentrated in the slag, and $\mathrm{Ni}$ and $\mathrm{Pb}$ are distributed among all three melts in rather similar concentrations. The distribution ratios of the present study generally agree with previous experimental data obtained for simplified two-melt systems. An oxidic dissolution of such forms as $\mathrm{NiO}, \mathrm{PbO}$ and $\mathrm{CoO}$ in the slag is reasonably acceptable, while the possibility of metallic dissolution of $\mathrm{Ag}, \mathrm{As}, \mathrm{Sb}$ and $\mathrm{Ni}$ in the slag cannot be denied.
\end{abstract}

(Received September 22, 1977)

\section{Introduction}

A series of research projects has been carried out by the authors ${ }^{(1)}$ to elucidate the thermodynamics of continuous smelting processes. The equilibrium relations between copper, white metal and iron silicate slag have already been described in a previous report ${ }^{(2)}$. In such a smelting process, distribution behavior $^{(3)(4)}$ of minor elements has important implications. In this paper, the experimental

* This paper was presented at the CIM 16th Annual Conference of Metallurgists held in Vancouver, Canada, August, 1977.

** The Research Institute of Mineral Dressing and Metallurgy, Tohoku University, Sendai. Present address, Nippon Mining Co., Saganoseki 879-22, Oita Prefecture, Japan.

*** The Research Institute of Mineral Dressing and Metallurgy, Tohoku University, Sendai 980, Japan.

Trans. JIM results of the distribution of silver, lead, nickel, cobalt, antimony and arsenic between the above three melts are described.

The distribution coefficients of the twoliquid systems of metal-matte and metal-slag have been reported, but only the operational data as reported by Mackey et al. ${ }^{(5)}$ is available for the three-liquid system.

\section{Experimental Method}

An experimental procedure similar to that described previously ${ }^{(2)}$ was used but with the addition of an impurity element. Namely, the starting materials containing metallic silver, lead, nickel, cobalt, antimony, or copper-arsenic alloy $(18 \% \mathrm{As})$ were kept at $1300^{\circ} \mathrm{C}$ for $45 \mathrm{~h}$ under a stream at $150 \mathrm{~m} \ell / \mathrm{min}$ of a $\mathrm{SO}_{2}$-Ar gas mixture having a controlled $\mathrm{SO}_{2}$ partial pressure. The $\mathrm{SO}_{2}$ pressure can be expected to be approximately proportional

1978 Vol. 19 
to the oxygen pressure. The amounts of lead, nickel, cobalt, antimony and arsenic added for $12 \mathrm{~g}$ of copper usually ranged from 0.1 to $0.6 \mathrm{~g}$, but a rather large and varying amount was added just for silver to carry out the preliminary experiment for the plain copperwhite metal-slag as described in the previous paper $^{(2)}$.

From the contents of impurity elements analyzed chemically for copper, white metal and slag, the distribution ratios for an element $\mathrm{X}$ were derived as follows:

$$
\begin{aligned}
& L_{\mathbf{x}}^{c / w}=(\% X)_{c} /(\% X)_{w} \\
& L_{\mathbf{x}}^{c / s}=(\% X)_{c} /(\% X)_{s} \\
& L_{\mathbf{x}}^{w / s}=(\% X)_{w} /(\% X)_{s}=L_{\mathbf{x}}^{c / s} / L_{\mathbf{x}}^{c / w}
\end{aligned}
$$

where $c, w$ or $s$ denotes each phase of copper, white metal or slag.

As the method of chemical analysis for impurity elements, the fire assay and the gravimetric method as $\mathrm{AgCl}$ were used for silver, the titration method following evaporation was adopted for arsenic, and the atomic absorption method was used for other elements.

\section{Distribution of Silver}

In the case of silver, the coexisting relation of three liquids of metal-matte-slag were first studied at $10 \mathrm{kPa}$ of $\mathrm{SO}_{2}$ gas, and then the distribution of silver between metal, matte and slag at a constant copper activity of 0.85 was measured as a function of the partial pressure of $\mathrm{SO}_{2}$ gas.

The coexisting relation of two liquids in the $\mathrm{Cu}-\mathrm{Ag}-\mathrm{S}$ system under $10 \mathrm{kPa}$ of $\mathrm{SO}_{2}$ gas is shown in Fig. 1, in which the points

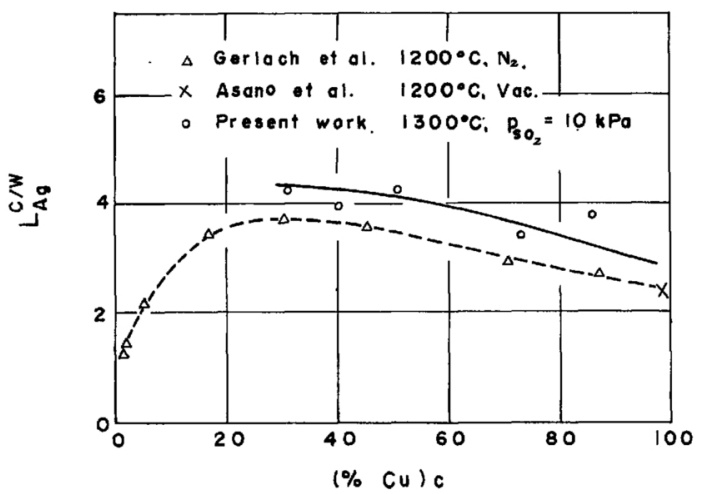

Fig. 2 Distribution ratio of silver between metal and matte plotted against the copper content in metal.

have been recalculated as the ternary $\mathrm{Cu}-\mathrm{Ag}-$ $\mathrm{S}$ by neglecting other minor elements. The copper content in the slag in this case has already been described in the previous paper ${ }^{(2)}$. From this figure, it can be observed that the distribution of silver in the metallic phase is higher than that in the matte. An isothermal section of the $\mathrm{Cu}-\mathrm{Ag}-\mathrm{S}$ system at $1200^{\circ} \mathrm{C}$ determined under nitrogen atmosphere was reported by Gerlach et al. ${ }^{(6)}$ as shown by the broken line in Fig. 1. Relations of the two results are rather similar though the experimental conditions are different.

In Fig. 2, the distribution ratio derived from Fig. 1 is plotted against the copper content in the metal. The present results show a slightly higher value than those obtained by Gerlach et al. ${ }^{(6)}$ Graphical extrapolation gives a distribution ratio of about 3 in dilute silver metal. Asano et al. ${ }^{(7)}$ investigated two-liquid equilibrium in the $\mathrm{Cu}-\mathrm{Ag}-\mathrm{S}$ system in an evacuated ampule, and reported $L_{\mathrm{Ag}}^{c / w}=2.4$

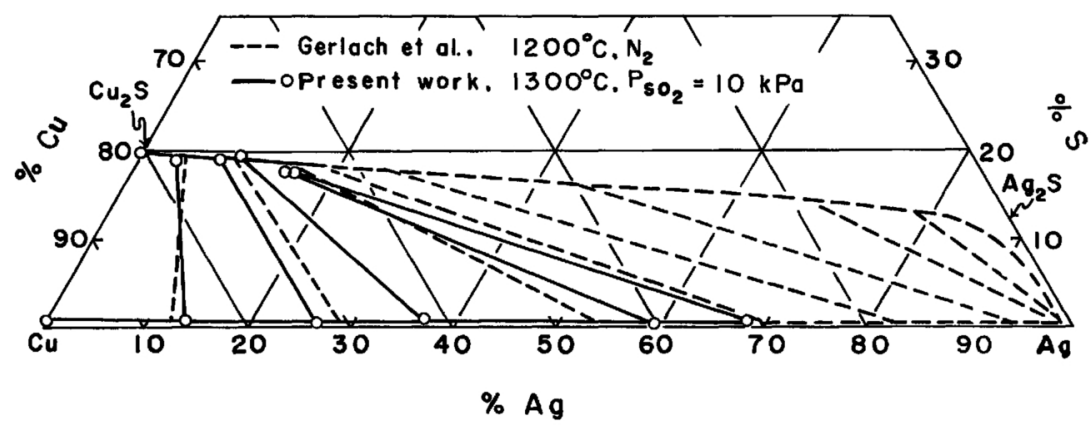

Fig. 1 The isothermal section of the $\mathrm{Cu}-\mathrm{Ag}-\mathrm{S}$ system. 


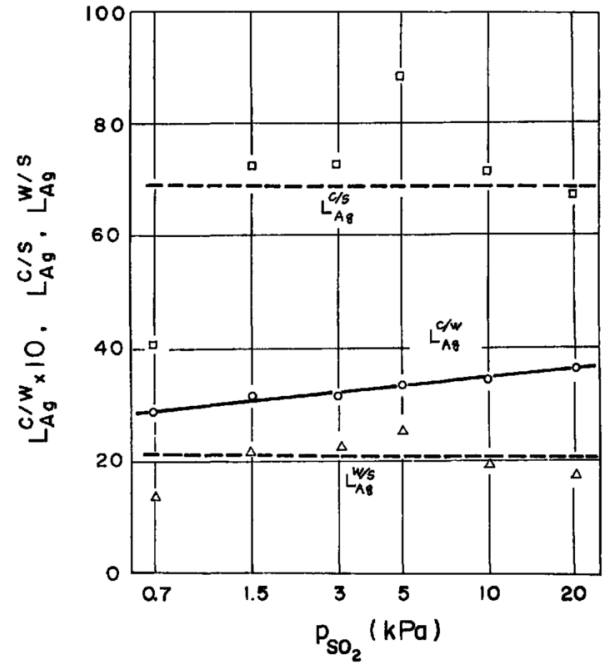

Fig. 3 The effect of $\mathrm{SO}_{2}$ partial pressure on the distribution ratios for silver at a constant copper activity of $\mathbf{0 . 8 5}$.

at $1200^{\circ} \mathrm{C}$ for the low silver content melts.

The effects of the $\mathrm{SO}_{2}$ partial pressure on the distribution ratios under a given activity of copper are shown in Fig. 3. The silver content in the metallic phase averages $27.3 \%$, and ignoring the effects of a small amount of $\mathrm{Fe}$, $\mathrm{O}$ and $\mathrm{S}$, the activity of copper is estimated to be around 0.85 from the literature ${ }^{(8)}$.

The content of silver in the slag was so small that the analytical value was inevitably not so reliable. Thus, as shown in Fig. $3, L_{\mathbf{A g}}^{c / s}$ and $L_{\mathbf{A g}}^{w / s}$ as illustrated by dashed lines, are scattered considerably. The effect of $\mathrm{SO}_{2}$ pressure is not clear, but at any rate silver is very poorly concentrated in the slag phase.

\section{Distributions of the Other Elements}

The experimental results obtained for the other elements are summarized in Table 1 with a partial pressure of $\mathrm{SO}_{2}$ in an equilibrating atmosphere.

It is estimated from the results that almost the whole amount of the charged nickel, cobalt and arsenic remained in the melts after $45 \mathrm{~h}$ of melting, but that the fractions remaining in the melts for lead and antimony were about 40 and $50 \%$ respectively. Such a loss would be caused partly by the vaporization of pure
Table 1 Analytical results for impurity elements $\mathrm{Pb}$, $\mathrm{Ni}, \mathrm{Co}, \mathrm{Sb}$ and $\mathrm{As}$ in the three melts with the partial pressure of $\mathrm{SO}_{2}$ controlled.

\begin{tabular}{|c|c|c|c|c|}
\hline \multirow{2}{*}{$X$} & \multirow{2}{*}{$\begin{array}{c}p_{\mathrm{SO}_{2}} \\
(\mathrm{kPa})\end{array}$} & \multicolumn{3}{|c|}{$\% \mathrm{X}$} \\
\hline & & in metal & in matte & in slag \\
\hline \multirow{5}{*}{ As } & 0.7 & 4.15 & 0.63 & 0.026 \\
\hline & 1.5 & 4.62 & 0.61 & 0.044 \\
\hline & 4.7 & 4.96 & 0.66 & 0.070 \\
\hline & 6.4 & 4.70 & 0.60 & 0.060 \\
\hline & 10 & 4.41 & 0.81 & 0.13 \\
\hline \multirow{6}{*}{$\mathrm{Sb}$} & 0.7 & 0.75 & 0.15 & 0.04 \\
\hline & 1.5 & 0.74 & 0.15 & 0.04 \\
\hline & 3 & 0.80 & 0.12 & 0.05 \\
\hline & 5 & 0.86 & 0.17 & 0.10 \\
\hline & 10 & 0.99 & 0.19 & 0.13 \\
\hline & 20 & 1.06 & 0.20 & 0.18 \\
\hline \multirow{5}{*}{$\mathrm{Pb}$} & 0.7 & 0.57 & 0.17 & 0.30 \\
\hline & 1.5 & 0.41 & 0.13 & 0.42 \\
\hline & 3 & 0.32 & 0.11 & 0.63 \\
\hline & 5 & 0.32 & 0.09 & 0.61 \\
\hline & 10 & 0.26 & 0.08 & 0.68 \\
\hline \multirow{5}{*}{$\mathrm{Ni}$} & 0.7 & 0.77 & 0.24 & 0.17 \\
\hline & 1.5 & 0.70 & 0.24 & 0.14 \\
\hline & 3 & 0.66 & 0.22 & 0.17 \\
\hline & 5 & 0.64 & 0.21 & 0.19 \\
\hline & 10 & 0.65 & 0.20 & 0.25 \\
\hline \multirow{8}{*}{ Co } & 0.7 & 0.083 & 0.083 & 0.58 \\
\hline & & 0.041 & 0.023 & 1.1 \\
\hline & 1.5 & 0.038 & 0.030 & 1.1 \\
\hline & 2 & 0.015 & 0.019 & 0.28 \\
\hline & 3 & 0.035 & 0.034 & 1.1 \\
\hline & 4.6 & 0.033 & 0.031 & 0.92 \\
\hline & 5 & 0.022 & 0.025 & 1.2 \\
\hline & 10 & 0.014 & 0.026 & 1.3 \\
\hline
\end{tabular}

metal before the formation of melts during heating. However, even if the entire loss of lead and antimony was caused by vaporization during melting at $1300^{\circ} \mathrm{C}$, the vaporization rate is not so fast that it disturbs the equilibrium among the melts. From the table, the distribution behavior of elements among the melts can be grouped into three classes. The first class is that in which the existence of an element in the system is biassed to the metal: $\mathrm{Ag}, \mathrm{As}$ or $\mathrm{Sb}$. The second class is that in which the existence of an element in the system is biassed to the slag: Co. The third class is that in which an element is distributed among all three melts in rather similar concentrations: $\mathrm{Ni}$ or $\mathrm{Pb}$. 


\section{Discussion}

\section{Distribution equilibria between metal and slag}

When a mononucleous oxide, $\mathrm{XO}_{v}$, is assumed to be in the form of $\mathrm{X}$ in the slag for the reaction

$$
\mathrm{X}+v \mathrm{Cu}+(v / 2) \mathrm{SO}_{2}=(v / 2) \mathrm{Cu}_{2} \mathrm{~S}+\mathrm{XO}_{v},
$$

the equilibrium constant $K$ is given by

$$
K_{1}=\left(\frac{a_{\mathrm{Cu}_{2} \mathrm{~S}}^{1 / 2}}{a_{\mathrm{Cu}}}\right)^{v} \cdot \frac{a_{\mathrm{XO}_{v}}}{a_{\mathrm{X}} \cdot P_{\mathrm{SO}_{2}}^{v / 2}} \approx \frac{a_{\mathrm{XO}_{v}}}{a_{\mathrm{X}} \cdot P_{\mathrm{SO}_{2}}^{v / 2}},
$$

because of the coexistence of nearly pure copper and white metal in the system. When the activity of the metallic form of $\mathrm{X}, a_{\mathrm{x}}$, is known, the activity of $\mathrm{XO}_{v}$ is calculated using the published free energy data.

The activity of an impurity in the metallic form can be calculated from the analytical result of metallic copper. Even if the fact that the copper metal in the present system contains around 1 percent of sulfur is taken into account, the following equation will be approximately valid when the level of impurity metal is not so high:

$$
a_{\mathrm{x}} \approx 0.64\left(\gamma_{\mathrm{x}}\right)_{c} \cdot(\% \mathrm{X})_{c} / M_{\mathrm{x}} .
$$

In the range having a small value of $(\% \mathrm{X})_{c}$, where $\left(\gamma_{\mathrm{x}}\right)_{c}$ is kept constant obeying Henry's law, $\left(\gamma_{\mathbf{x}}\right)_{c}$ can be estimated from the literature data neglecting the influence of other solutes.

The activity of $\mathrm{XO}_{v}$ in the slag can be approximately represented as follows:

$$
a_{\mathrm{XO}_{v}} \approx \frac{\left(\gamma_{\mathrm{XO}_{v}}\right)_{s}(\% \mathrm{X})_{s}}{M_{\mathrm{x}} \cdot\left(n_{\mathrm{T}}\right)_{s}} \approx \frac{\left(\gamma_{\mathrm{XO}_{v}}\right)_{s}(\% \mathrm{X})_{s}}{1.48 M_{\mathrm{x}}},
$$

where $\left(n_{T}\right)_{s}$ is a summation of the ratios of weight percentages of slag components to their molar weights. Based upon the previous experimental data ${ }^{(2)}$, the value of $\left(n_{T}\right)_{s}$ for $100 \mathrm{~g}$ of $\mathrm{CuO}_{0.5}-\mathrm{FeO}-\mathrm{FeO}_{1.5}-\mathrm{SiO}_{2}-\mathrm{XO}_{v}$ slag can reasonably be assumed to be 1.48 .

Combining eqs. (2), (3) and (4), the following relation can be derived:

$$
L_{\mathrm{x}}^{c / s}=\frac{(\% \mathrm{X})_{c}}{(\% \mathrm{X})_{s}}=\frac{\left(\gamma_{\mathrm{XO}_{v}}\right)_{s}}{0.95 K_{1} \cdot\left(\gamma_{\mathrm{X}}\right)_{c} \cdot P_{\mathrm{SO}_{2}}^{\nu / 2}},
$$

When the ratio $\left(\gamma_{\mathrm{Xo}_{v}}\right)_{s} /\left(\gamma_{\mathrm{X}}\right)_{c}$ is kept constant as in cases where the impurity element shows the Henrian behavior in both metal and slag phases, it can be expected that the $L_{\mathbf{x}}^{c / s}$ is reversely proportional to $p_{\mathrm{SO}_{2}}^{\mathrm{v} / 2}$.

The experimental results showing the relation between $L_{\mathbf{x}}^{c / s}$ and $p_{\mathrm{SO}_{2}}$ are illustrated in Fig. 4 using logarithmic scales. The apparent distribution ratio for copper can be derived from the previous data ${ }^{(2)}$, and is illustrated by a dashed line together with the data for silver, because these data were obtained for highly concentrated melts. As described above, linear relations are expected to depend on $v$ as is demonstrated at the top of the figure. It is difficult to define exact dissolved forms of impurities from the experimental results because of the narrow $p_{\mathrm{SO}_{2}}$ range investigated and the inevitable scattering in the distribution ratios. In Fig. 4, however, all the elements except for silver in this study seem to act in oxidic mononucleous forms. Assuming XO for the dissolved species of $\mathrm{X}$ in the slag, the solid lines for nickel, lead and cobalt are drawn in the figure.

The activity coefficients of $\mathrm{XO}$ in the slag

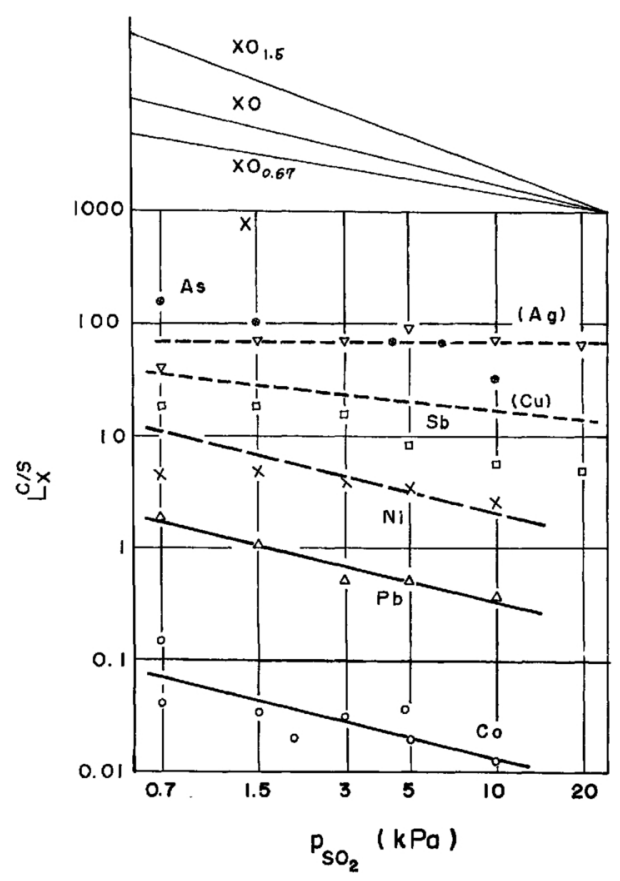

Fig. 4 The relation between $L_{\mathbf{x}}^{c / s}$ and $p_{\mathrm{SO}_{2}}$ for minor impurity elements. 
were calculated for nickel, lead and cobalt from the analytical results, the published free energy data $^{(9)(10)}$ and the activity coefficients ${ }^{(11)(12)}$ for the copper alloy system. The averaged values are 0.25 for $\mathrm{PbO}$, which agree with Meyer et al. ${ }^{(13)}, 3$ for $\mathrm{NiO}$, which agree with Grimsey et al. ${ }^{(14)}$, and 0.8 for CoO. Nagamori et al. ${ }^{(15)}$ claimed that arsenic and antimony are dissolved in slag in the atomic state. From a rough evaluation of the data shown in Fig. 4, the oxidic dissolution in the form of $\mathrm{AsO}_{1.5}$ or $\mathrm{SbO}_{1.5}$ is acceptable if $0.02 \%$ As or $0.03 \% \mathrm{Sb}$ is dissolved in the atomic state, and the activity coefficient of $\mathrm{SbO}_{1.5}$ can be estimated to be around 0.4. Although further investigation is required, these elements including nickel might exist in slag under mixed states of metal and oxide.

Judging from Fig. 4, the order of concentration tendencies in the metal phase under the conditions investigated can be arranged as

$$
\text { As, }(\mathrm{Ag})>(\mathrm{Cu})>\mathrm{Sb}>\mathrm{Ni}>\mathrm{Pb}>\mathrm{Co} \text {. }
$$

The detrimental elements of arsenic and antimony are highly concentrated in the metal phase, while the valuable cobalt tends to be lost into the slag.

Distribution ratios similar to those of the present study were reported by Mackey et al. ${ }^{(5)}$ based on the actual operations of the Noranda copper making process. Although the general trends are similar, the values of $L_{\mathbf{x}}^{c / s}$ themselves are lower than those in the present work. This difference in the absolute values is caused by the entrapment of metal droplets in the slag as was referred to by Mackey et al.

Nagamori et al. ${ }^{(15)}$ investigated the distribution relation of impurity elements between metallic copper and slag excluding the matte phase by the use of a gas stream of the CO$\mathrm{CO}_{2}$ mixture. In general, their results for lead, antimony and arsenic agree with those in the present study. Therefore, the essential equilibrium relation does not seem to be seriously affected by the existence of the matte phase or sulfur.

\section{Distribution ratio between metal and matte}

If the mononucleous sulfidic form, $\mathrm{XS}_{\beta}$, can be assumed to be the impurity element in the white metal, then the following equilibrium reaction is of use:

$$
\begin{aligned}
& \mathrm{X}+\beta \mathrm{Cu}_{2} \mathrm{~S}=\mathrm{XS}_{\beta}+2 \beta \mathrm{Cu}, \\
& K_{6}=\left(\frac{a_{\mathrm{Cu}^{2}}^{2}}{a_{\mathrm{Cu}_{2} \mathrm{~S}}}\right)^{\beta} \cdot\left(\frac{a_{\mathrm{XS}_{\beta}}}{a_{\mathrm{X}}}\right) \approx \frac{a_{\mathrm{XS}_{\beta}}}{a_{\mathrm{X}}} .
\end{aligned}
$$

Ignoring the slight amount of iron and oxygen in the white metal, the activity of $\mathrm{XS}_{\beta}, a_{\mathrm{xs}_{\beta}}$, is represented as follows:

$$
a_{\mathrm{xs}_{\beta}}=\left(\gamma_{\mathrm{Xs}_{\beta}}\right)_{w} \cdot N_{\mathrm{Xs}_{\beta}} \approx 1.59\left(\gamma_{\mathrm{Xs}_{\beta}}\right)_{w} \cdot(\% \mathrm{X})_{w} / M_{\mathrm{x}}
$$

By a combination and rearrangement of eqs. (3), (7) and (8), the following relation can be derived:

$$
L_{\mathbf{x}}^{c / w}=\frac{(\% \mathrm{X})_{c}}{(\% \mathrm{X})_{w}}=\frac{2.5}{K_{6}} \cdot \frac{\left(\gamma_{\mathrm{XS}_{\beta}}\right)_{w}}{\left(\gamma_{\mathrm{X}}\right)_{c}} .
$$

If the Henrian behaviors can be assumed for impurity elements, the distribution ratio between metal and matte is independent of $p_{\mathrm{SO}_{2}}$. The distribution ratios derived from the experimental results are plotted against the $p_{\mathrm{SO}_{2}}$ in Fig. 5, suggesting that the dependence on $\mathrm{SO}_{2}$ pressure is hardly observed.

The estimation of apparent activity coefficients of sulfides give $\gamma_{\mathrm{NiS}_{0.67}} \approx 1$ (the data for $\mathrm{Ni}_{3} \mathrm{~S}_{2}$ derived by Takewaki et al. ${ }^{(16)}$ was used), $\gamma_{\mathrm{PbS}} \approx 3$ and $\gamma_{\mathrm{COS}_{0.89}} \approx 0.2$ approximately, but it is believed that the principal forms of arsenic, antimony and even lead in the white metal will be metallic.

From Fig. 5, it can be seen that all of the elements except cobalt are concentrated in the metal phase rather than in the matte phase. The order of the distribution ratios among them is as follows:

$$
\mathrm{As}>\mathrm{Sb}>\mathrm{Pb}, \mathrm{Ni},(\mathrm{Ag})>\mathrm{Co},(\mathrm{Cu}) \text {. }
$$

There is a strong tendency for both As and $\mathrm{Sb}$ to be rejected by the matte and this property may represent a strong possibility of the formation of a metallic form in the melts.

The distribution equilibria in the rather simple system of two melts of copper and white metal in an evacuated ampule have been reported by several investigators. Asano et al. ${ }^{(17)}$ gave the value for lead to be between 4 and 12 


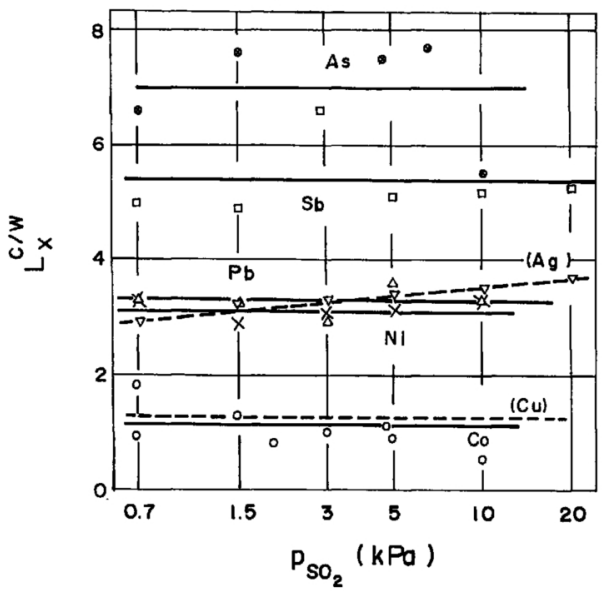

Fig. 5 The relation between $L_{\mathbf{x}}^{c / w}$ and $p_{\mathrm{SO}_{2}}$ for minor impurity elements.

at $1200^{\circ} \mathrm{C}$ in the range from 1.3 to $5.5 \% \mathrm{~Pb}$ in the metal. The value of 3.2 reported by Azuma et $a .^{(17)}$ is more agreeable with the present results. For $\mathrm{Ni}$, based upon the data reported by Asano et al. ${ }^{(17)}, L_{\mathrm{Ni}}^{c / w}=2.7$ is derived at $1300^{\circ} \mathrm{C}$. The value agrees well with the present results. From the data reported by Nagamori et al. ${ }^{(18)}, L_{\mathrm{Sb}}^{c / w}=5$ and $L_{\mathrm{As}}^{c / w}=27$ are derived at $1300^{\circ} \mathrm{C}$, and $L_{\mathrm{Sb}}^{c / w}$ agrees well with the results of this study although $L_{\mathrm{As}}^{c / w}$ is three times greater than the results of this study. Asano et al. ${ }^{(19)}$ showed the values at $1200^{\circ} \mathrm{C}$ to be $L_{\mathrm{Sb}}^{c / w}=13.58$ and $L_{\mathrm{As}}^{c / w}=5 \sim 10$. In general, the distribution ratio between metal and matte does not seem to be affected by the coexisting slag components such as iron and oxygen.

\section{Distribution ratio between white metal and slag}

The experimental results for the distribution ratio between white metal and slag are shown in Fig. 6. The general trends are similar to those shown in Fig. 4, but detailed discussions are impossible because of the complexity of the existing forms of these elements.

The order of the tendency to concentrate in the matte phase is as follows:

$$
(\mathrm{Cu}),(\mathrm{Ag})>\mathrm{As}>\mathrm{Sb}>\mathrm{Ni}>\mathrm{Pb}>\mathrm{Co} \text {. }
$$

As presented by Mackey et al. ${ }^{(5)} \mathrm{As}$ and $\mathrm{Sb}$ are more highly concentrated in the white metal

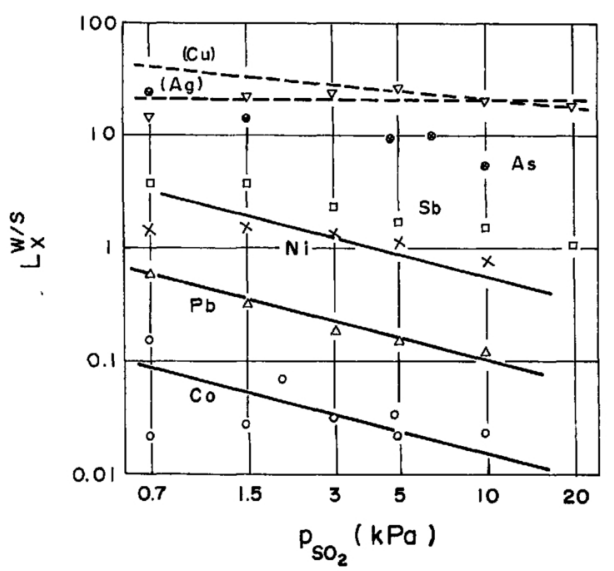

Fig. 6 The relation between $L_{\mathbf{x}}^{w / s}$ and $p_{\mathrm{SO}_{2}}$ for minor impurity elements.

as compared with the conventional matte smelting conditions.

\section{Conclusion}

The distribution equilibria of impurity elements $\mathrm{Ag}, \mathrm{Ni}, \mathrm{Co}, \mathrm{Pb}, \mathrm{Sb}$ and $\mathrm{As}$ for three melts of metal, matte and silica-saturated iron silicate slag at $1300^{\circ} \mathrm{C}$ have been investigated experimentally under a controlled $\mathrm{SO}_{2}$ pressure varying from 0.7 to $20 \mathrm{kPa}$.

From the results the following conclusions have been derived, which are important in relation to the industrial processes of copper making.

(1) Major parts of $\mathrm{Ag}, \mathrm{As}$ and $\mathrm{Sb}$ are concentrated in the metallic phase.

(2) A major part of $\mathrm{Co}$ is concentrated in the slag.

(3) $\mathrm{Ni}$ and $\mathrm{Pb}$ are distributed among all three melts in rather similar concentrations.

In comparison with other studies of rather simplified two-liquid systems, the distribution ratios in this three-liquid system are not so different.

Thermodynamic treatments of the experimental results suggest that the impurity elements are dissolved in the slag in the oxidic form such as $\mathrm{NiO}, \mathrm{PbO}, \mathrm{CoO}$, etc, but the possibility of dissolution in metallic form cannot be denied for $\mathrm{Ag}, \mathrm{As}, \mathrm{Sb}$ and even for $\mathrm{Ni}$. It is postulated that the metallic form becomes more stable in the white metal phase. 


\section{REFERENCES}

(1) A. Yazawa and M. Eguchi: Extractive Metallurgy of Copper, J. C. Yannopoulos and J. C. Agarwal ed., AIME, (1976), vol. 1, 3.

(2) M. Eguchi and A. Yazawa: Trans. JIM, 18 (1977), 353.

(3) A. Yazawa: Can. Met. Quart., 13 (1974), 443.

(4) A. Yazawa and T. Azakami: Can. Met. Quart., 8 (1969), 257.

(5) P. J. Mackey, G. C. Mckerrow and P. Tarassoff: Paper presented at the 104th AIME Annual Meeting, New York, February 16-20, 1975.

(6) J. Gerlach, U. Hennich and K. Trettin: ERZMETALL, 19 (1966), 458.

(7) N. Asano, K. Wase and M. Kobayashi: J. Min. Met. Inst. Japan, 87 (1971), 347.

(8) R. Hultgren, P. Desai, M. Gleiser and K. Kelley: Selected values of the thermodynamic properties of binary alloys, ASM, (1973), 44.

(9) F. Richardson and J. Jeffes: J. Iron Steel Inst., 171 (1952), 165.
(10) J. Coughlin: U.S. Bur. Mines Bull. No. 542, (1954).

(11) T. Azakami and A. Yazawa: Can. Met. Quart., 15 (1976), 1.

(12) G. K. Sigworth and J. F. Elliott: Can. Met. Quart., 13 (1974), 455.

(13) H. W. Meyer, J. B. Nolan and F. O. Richardson: Trans. Inst. Min. Met., 75C (1966), 121.

(14) E. J. Grimsey and A. K. Biswas: Trans. Inst. Min. Met., 85 (1976), C 200.

(15) M. Nagamori, P. J. Mackey and P. Tarassoff: Met. Trans., 6B (1975), 295.

(16) M. Takewaki, T. Azakami and M. Kameda: Bull. Res. Inst. Min. Dress. Metall. Tohoku Univ., 28 (1972), 113.

(17) N. Asano and T. Ichio: Suiyokaishi, 14 (1962), 467.

(18) M. Nagamori, P. J. Mackey and P. Tarassoff: Met. Trans., 6B (1975), 197.

(19) N. Asano and M. Wada: Suiyokaishi, 16 (1968), 385. 